ARTICLE

Received 21 Apr 2015 | Accepted 19 Oct 2015 | Published 17 Nov 2015

DOI: $10.1038 /$ ncomms 9939

OPEN

\title{
Fennoscandian freshwater control on Greenland hydroclimate shifts at the onset of the Younger Dryas
}

Francesco Muschitiello', Francesco S.R. Pausata ${ }^{2}$, Jenny E. Watson ${ }^{3}$, Rienk H. Smittenberg', Abubakr A.M. Salih², Stephen J. Brooks ${ }^{4}$, Nicola J. Whitehouse ${ }^{3,5}$, Artemis Karlatou-Charalampopoulou ${ }^{6} \&$ Barbara Wohlfarth ${ }^{1}$

Sources and timing of freshwater forcing relative to hydroclimate shifts recorded in Greenland ice cores at the onset of Younger Dryas, $\sim 12,800$ years ago, remain speculative. Here we show that progressive Fennoscandian Ice Sheet (FIS) melting 13,100-12,880 years ago generates a hydroclimate dipole with drier-colder conditions in Northern Europe and wetter-warmer conditions in Greenland. FIS melting culminates 12,880 years ago synchronously with the start of Greenland Stadial 1 and a large-scale hydroclimate transition lasting $\sim 180$ years. Transient climate model simulations forced with FIS freshwater reproduce the initial hydroclimate dipole through sea-ice feedbacks in the Nordic Seas. The transition is attributed to the export of excess sea ice to the subpolar North Atlantic and a subsequent southward shift of the westerly winds. We suggest that North Atlantic hydroclimate sensitivity to FIS freshwater can explain the pace and sign of shifts recorded in Greenland at the climate transition into the Younger Dryas.

\footnotetext{
${ }^{1}$ Department of Geological Sciences and Bolin Centre for Climate Research, Stockholm University, SE-10691 Stockholm, Sweden. ${ }^{2}$ Department of Meteorology and Bolin Centre for Climate Research, Stockholm University, SE-10691 Stockholm, Sweden. ${ }^{3}$ School of Geography, Archaeology and Palaeoecology, Queen's University Belfast, Belfast BT7 1NN, UK. ${ }^{4}$ Department of Entomology, Natural History Museum, Cromwell Road, London SW7 5BD, UK. ${ }^{5}$ School of Geography, Earth and Environmental Sciences, Plymouth University, Drake Circus, Plymouth PL4 8AA, UK. ${ }^{6}$ Department of GeologyQuaternary Sciences, Lund University, Sölvegatan, 12,22362 Lund, Sweden. Correspondence and requests for materials should be addressed to F.M. (email: francesco.muschitiello@geo.su.se).
} 
T he Younger Dryas cold stadial (YD; 12,800-11,650 year $\mathrm{BP})$ is the latest major large-scale climate shift in the North Atlantic domain, providing an exceptional natural laboratory to improve our understanding of rapid climate change. The conventional explanation for the YD involves a catastrophic meltwater outburst from the Laurentian Ice Sheet into the North Atlantic that triggered a widespread reorganization of the atmosphere-ocean system ${ }^{1-3}$. However, the chronological thread linking Laurentian freshwater events and the timing of abrupt hydroclimate shifts observed in template records such as Greenland ice cores still remains equivocal ${ }^{3-7}$.

Recent studies ${ }^{8-10}$ have moved away from the classical flood hypothesis and demonstrated that gradual freshwater input from the Fennoscandian Ice Sheet (FIS) - rather than from the Laurentian Ice Sheet-may have been sufficient to trigger cold stadials during the last glacial cycle. Through southward storm track shifts, mediated by build-up of sea ice in the Nordic Seas, FIS meltwater fluxes at the end of interstadials emerge as a critical factor for reconciling the timing and amplitude of the rapid interstadial/stadial transitions observed in Greenland. Nevertheless, the coherency of these processes during the last glacial-interglacial transition, the Last Termination, is largely unexplored. Furthermore, it remains an open question as to what extent the North Atlantic hydroclimate patterns responded to FIS freshwater forcing at the inception of the YD.

Here we combine a new hydroclimate reconstruction from Northern Europe with transient climate model simulations to show that North Atlantic atmospheric circulation was sensitive to FIS meltwater at the end of the Last Termination. Our conclusions are critical for the interpretation of Greenland icecore records and could help to target future paleoclimate model simulations.

\section{Results}

FIS meltwater signal propagation into hydroclimate records. In this study, we reconstruct the regional sequence of hydroclimate events at the onset of the YD using the hydrogen isotope composition of lipid biomarker records from Hässeldala Port (HÄ) lake sediments, Southern Sweden. HÄ is a small ancient lake ${ }^{11,12}$ located along the south coast of Sweden $\left(56^{\circ} 16^{\prime} \mathrm{N}\right.$; $15^{\circ} 03^{\prime} \mathrm{E}$ ) and downwind of the primary drainage route of the FIS (Fig. 1). Under modern conditions, precipitation is delivered to HÄ by the prevailing westerly winds mainly from the North Sea, the Skagerrak-Kattegat basin and from local continental sources (Fig. 1a). On the other hand, moist air from the Baltic Sea only occurs under exceptionally warm surface water conditions ${ }^{13}$. At multidecadal scales, the amount of moisture transported to HÄ from marine sources primarily depends on surface-water temperatures, which control water-to-air vapour fluxes (Fig. 1b). During the Last Termination, moisture transport from the ice-dammed Baltic Ice Lake ${ }^{14}$ was probably negligible owing to low surface temperatures of glacial lake waters inhibiting moisture fluxes, and to the dominant westerly winds ${ }^{15}$ (Fig. 1c). Therefore, hydroclimate proxies from HÄ sediments are ideally suited for reconstructing the signal of FIS meltwater flux to the adjacent seaboard of the Nordic Seas (Fig. 1d) integrated as isotopic depletions in the hydrogen stable isotope composition of the target precipitation.

Proxy records and meltwater reconstruction. We analysed the $\delta D$ composition of $n-C_{21}$ and $n-C_{27-29-31}$ alkanes (Methods; Supplementary Figs 1 and 2; Supplementary Data 1), which in HÂ sediments are representative components of distinct aquatic and terrestrial sources, respectively (Supplementary Discussion). $\delta D$ values of aquatic $\left(\delta D_{\text {aq }}\right)$ and terrestrial $\left(\delta D_{\text {terr }}\right) n$-alkanes are established indicators of the isotopic composition of summer precipitation $\delta D$ (refs 16,17), which is controlled-at mid-to-high latitudes-by condensation temperature and moisture source composition $^{18}$. Furthermore, $\delta D_{\text {terr }}$ can offset $\delta D_{\text {aq }}$ owing to evaporative enrichment $\left(\Delta \delta D_{\text {terr }- \text { aq }}\right)$ due to the combined effect of soil evaporation and leaf water transpiration, evapotranspiration, thus serving as an indicator of moisture availability and relative humidity ${ }^{19}$ (Supplementary Figs 3 and 4).

The interpretation of the biomarker record is supported by quantitative summer temperature estimations based on fossil chironomids (Methods; Supplementary Data 1). Moreover, HÄ's chronology is based on an age-depth model of 49 AMS ${ }^{14} \mathrm{C}$ dates covering $\sim 4,000$ years (Methods; Supplementary Figs 5-7; Supplementary Table 1). After the recent synchronization of the ${ }^{14} \mathrm{C}$ and ice-core time scales using the common cosmogenic radionuclide variations ${ }^{20}$ (Supplementary Methods), the age-depth model allows for a consistent and accurate comparison to Greenland stratigraphic events. Hence, $\mathrm{HÄ}$ proxies are here compared to NGRIP $\delta^{18} \mathrm{O}$ records $^{21}$ and all ice-core ages are hereafter reported as calibrated ${ }^{14} \mathrm{C}$ years before 1950 (BP).

To better decipher the regional hydroclimate expressions in Greenland and Northern Europe and their potential links, we also compare the NGRIP deuterium excess $d$ (ref. 22) and GRIP snow accumulation rates $^{23}$ with $\mathrm{HÄ} \delta D_{\mathrm{aq}}$ and $\Delta \delta D_{\text {terr }- \text { aq }}$ records. The $d$-excess provides information on the Greenland's moisture source and summer precipitation $\operatorname{rates}^{24}$. The $\delta D_{\mathrm{aq}}$ is interpreted here as a proxy for changes in precipitation-source $\delta D$ after accounting for local hydrologic and vegetation effects and following correction for global ice volume and isotope fractionation factors $\left(\delta D_{\text {corr }}\right.$; Supplementary Methods; Supplementary Fig. 8). The $\delta D_{\text {corr }}$ records shifts in distillation of water vapour associated with the marine moisture source $^{25}$-primarily the North Sea and the Skagerrak-Kattegat at the temporal resolution of our records-and associated with regional land surface recycling of evaporated moisture ${ }^{26}$. The $\delta D_{\text {corr }}$ is largely controlled by FIS loss through the introduction of isotopically depleted meltwater in the moisturesource area. Moreover, meltwater discharge causes decreases in source seawater salinity, surface temperatures, in source moisture uptake and rainout during transport ${ }^{18}$, all resulting in more negative $\delta D$ of precipitation and drier air reaching HÄ. Hence, we regard the $\delta D_{\text {corr }}$ and $\Delta \delta D_{\text {terr-aq }}$ records as qualitative indicators of FIS freshwater supply to the adjacent Nordic Seas.

Data interpretation. The HÄ $\delta D_{\text {aq }}$ and $\Delta \delta D_{\text {terr - aq }}$ records show a remarkable two-step decrease and increase, respectively, starting shortly before the onset of the YD as defined in the pollenstratigraphy $^{11}$ (Fig. 2). Similarly, after a $\sim 300$-year long summer warming of up to $4{ }^{\circ} \mathrm{C}$ during the Allerød pollen zone (AL), chironomid-inferred temperatures indicate a prominent two-step cooling preceding the start of the YD (Fig. 2). In the first step $\delta D_{\mathrm{aq}}$ values start to decrease by $25 \%$ at $13,090 \pm 37$ year BP $( \pm 1 \sigma)$ and reach an isotopic minimum at $12,883 \pm 35$ year BP. This $\delta D_{\text {aq }}$ decline coincides with a $27 \%$ rise in $\Delta \delta D_{\text {terr-aq, }}$, peaking at $12,883 \pm 35$ year $\mathrm{BP}$, and a $\sim 2^{\circ} \mathrm{C}$ decrease in summer temperatures (Fig. 2), suggesting substantially drier and colder summer conditions. After a brief recovery, a second step occurs. At $12,700 \pm 52$ year $\mathrm{BP}, \delta D_{\mathrm{aq}}$ values decrease again by at least $34 \%$. The drop in $\delta D_{\mathrm{aq}}$ values straddles the pollen-stratigraphic $\mathrm{AL}-\mathrm{YD}$ transition, which is a regional marker for major environmental changes resulted from hemispheric-scale cooling $^{27}$ (Fig. 2). This shift coincides with a $26 \%$ rise in $\Delta \delta D_{\text {terr-aq }}$ and a $\sim 3{ }^{\circ} \mathrm{C}$ decrease in summer temperatures, 

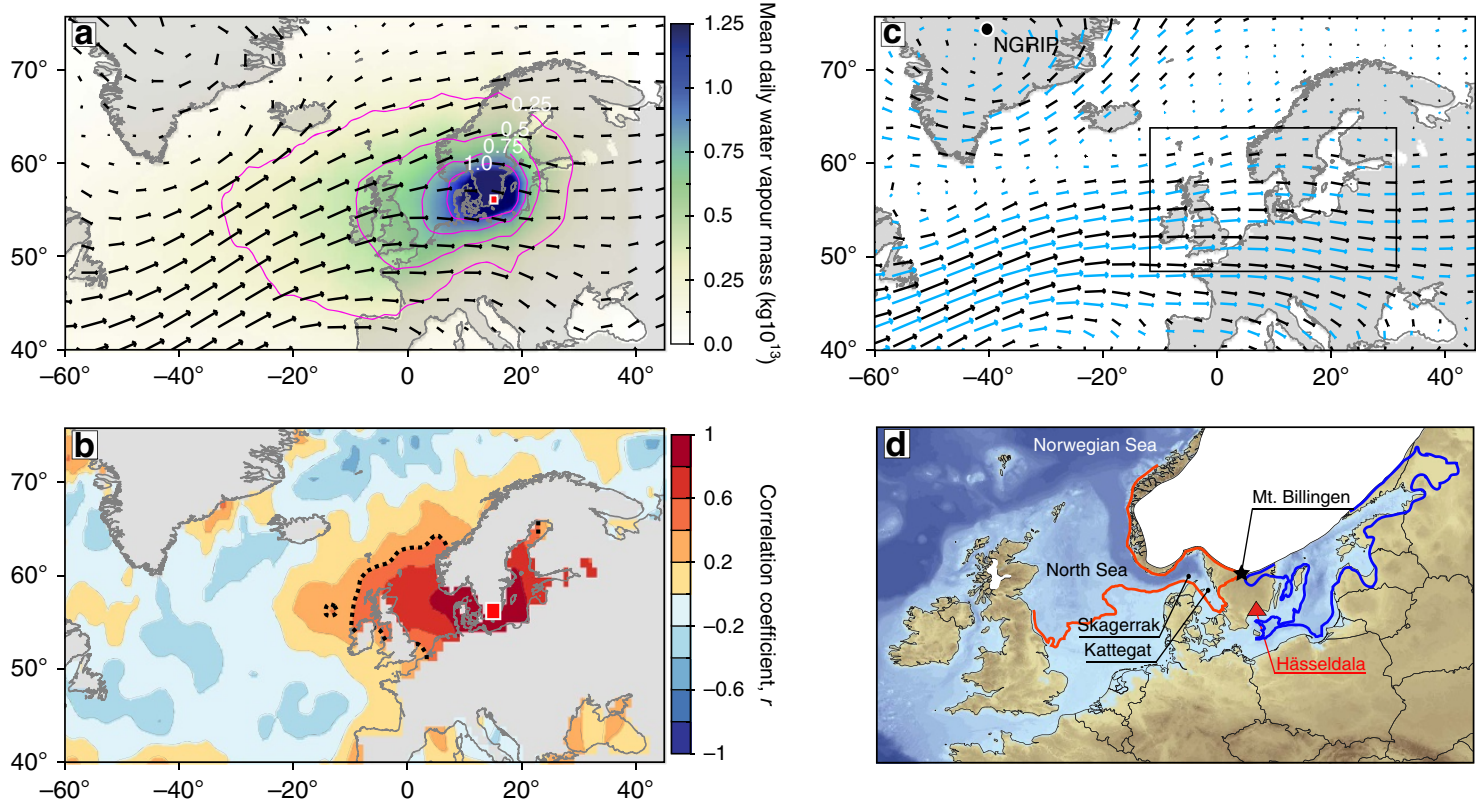

Figure 1 | Modern and past summer atmospheric circulation over Southern Sweden and the North Atlantic. (a) Precipitation source distribution showing averaged daily water vapour mass (1998-2008) transported to the location of Hässeldala, target of precipitation (red box). Results are plotted together with climatology of $850 \mathrm{hPa}$ wind fields in the North Atlantic region (NCEP/NCAR; 1979-2009). (b) Climatological field correlations between specific humidity (HadCRUH; 1974-2003) at Hässeldala (red box) and SSTs (HadSST1), showing the relation between moisture mass transported to the target and surface water temperatures at the marine moisture sources. Significance levels are indicated by black dashed lines (95\%). (c) Climatological $850 \mathrm{hPa}$ wind fields during the regional Allerød (black arrows) and Younger Dryas (cyan arrows) pollen zones as modelled in the TraCE simulations ${ }^{33,44}$. Location of the NGRIP ice core is indicated. The black box highlights the area shown in d. (d) Location of Hässeldala (red triangle) in Southern Sweden and paleogeographic setting. The extension of the Baltic Ice Lake (blue dashed line) and palaeogeography of the North Sea (orange dashed line) during the Allerød pollen zone are also displayed. The black star indicates the location of the Baltic Ice Lake's outlet at Mt. Billingen in south-central Sweden ${ }^{14}$.

indicating a further change towards drier and colder summer conditions.

In contrast, the synchronized NGRIP record shows that the first decline in $\delta D_{\mathrm{aq}}$ values at $\mathrm{HÄ}$ coincides with rising $\delta^{18} \mathrm{O}$ values, corresponding to the warm Greenland Interstadial 1a (GI-1a). The local $\delta D_{\text {aq }}$ minima and $\Delta \delta D_{\text {terr-aq }}$ maxima at $\mathrm{HÄ}$ are synchronous with the start of the cold Greenland Stadial 1 (GS-1; 12,882 \pm 13 year BP; Fig. 2), defined in NGRIP ice cores as a rapid shift in $d$-excess ${ }^{22}$. Conversely, the second decline in $\delta D_{\text {aq }}$ values at $\mathrm{HÄ}$ occurs when NGRIP $\delta^{18} \mathrm{O}$ had already reached minimum values.

The comparison of $H \ddot{A} \delta D_{\text {corr }}$ and $\Delta \delta D_{\text {terr-aq }}$ records with NGRIP $d$-excess and GRIP accumulation rates shows two separate phases during GI-1a and during the first $\sim 180$ years of GS-1 (Fig. 3). Each of these are characterized by a hydroclimate dipole across the eastern North Atlantic. GI-1a is marked by increasingly fresher North Sea surface conditions and inhibited moisture transport to HÄ. This interval coincides with a progressive north-eastward shift of the North Atlantic source of Greenland precipitation (more proximal) and with enhanced moisture transport to the summit ${ }^{24}$.

At the GI-1a/GS-1 transition, FIS meltwater discharge culminates and the hydroclimate dipole rapidly inverts its sign, marking the start of a brief hydroclimatic recovery, which lasted for $\sim 180$ years. This $\sim 180$-year-long interval, which represents a transitional phase between the onset of GS-1 in Greenland and North Hemispheric cooling 17,27 , appears to have been characterized by a temporary return to more saline conditions in the North Sea and stronger advection of moisture to HÄ. By contrast, the moisture source of Greenland precipitation moves south-westwards (more distant), resulting in less effective moisture transport to the summit ${ }^{24}$. This transition has been attributed to a southward diversion of the westerly winds and stronger zonal circulation owing to sea-ice expansion in the North Atlantic ${ }^{17}$. Consistent with modern observations ${ }^{28}$, stronger zonal winds can more efficiently route warm and saline North Atlantic waters to the North Sea, but also cause a south-westward shift of Greenland's precipitation source ${ }^{24}$.

After the $\sim 180$-year-long transitional phase and coinciding with the regional AL-YD pollen-zone boundary, Greenland's hydroclimate stabilized to a stadial mode. The establishment of stadial conditions in Southern Sweden occurred, however, one century later when progressive freshening of surface waters in the North Sea caused a gradual drop in summer temperatures and precipitation (Figs 2 and 3). We interpret these asynchronous events as an expression of the southward migration of North Atlantic storm tracks $^{17}$ coincident with a gradually more persistent summer sea-ice growth in the Nordic $\mathrm{Seas}^{29}$.

The succession of surface freshening/salification events inferred from HÄ records through GI-1a and GS-1 is in line with reconstructions from the Skattegat-Kattegat ${ }^{30}$, the North Sea ${ }^{31}$ and the Norwegian Sea ${ }^{29,32}$. We thus suggest that increasingly stronger melting of the FIS in response to the Late AL warming (Fig. 2) played a central role in the hydrological cycle of the eastern North Atlantic at the transition into the YD climatic reorganization.

Climate model simulations. To investigate our hypothesis, we turn to a transient simulation of the last 21,000 years performed with a coupled atmosphere-ocean climate model ${ }^{33}$ (Methods). The model shows great sensitivity of regional climate to a relatively weak FIS freshwater pulse $(0.011 \mathrm{~Sv})$ in the Nordic Seas during the Late AL. The freshwater forcing generates a summer 


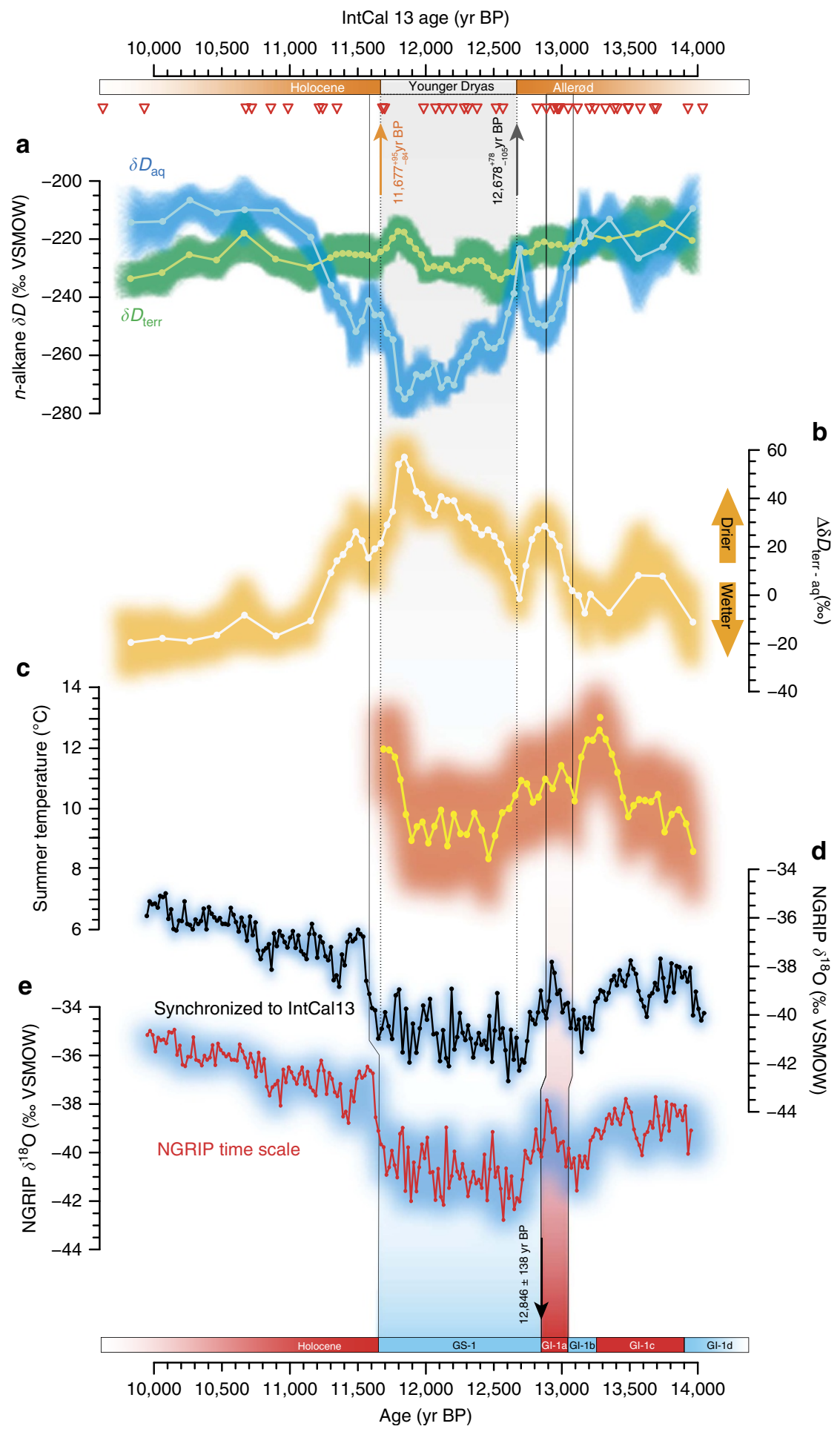

Figure 2 | Paleoclimate proxy data from Hässeldala and the Greenland ice core record. $\delta D$ values of (a) $n-C_{21}$ (aquatic plants $\delta D_{\text {aq; }}$ blue) and weighted average of $\delta D$ values of $n-C_{27-29-31}$ based on relative $n$-alkane abundances (higher terrestrial plants $\delta D_{\text {terri }}$ green), as well as (b) terrestrial evapotranspiration ( $\Delta \delta D_{\text {terr-aq }}$ ) and (c) chironomid-based summer temperatures during the regional YD pollen zone at Hässeldala compared to (d,e) the NGRIP $\delta^{18} \mathrm{O}$ record ${ }^{21}$. The NGRIP record is plotted both on its original time scale and on the IntCal13 time scale (see text for details) after synchronization between the ice-core ${ }^{10} \mathrm{Be}$ and tree-ring ${ }^{14} \mathrm{C}$ time scales ${ }^{20}$. Beyond 13,500 years $\mathrm{BP}$, which is the limit of the synchronization between the time scales, we reset the GICCO5 cumulative counting error ${ }^{21}$. Red triangles denote ${ }^{14} \mathrm{C}$ chronological constraints used in the final age-depth model. All records are presented with shadings indicating empirical $95 \%$ uncertainty bounds based on analytical and age-model errors. The Hässeldala pollen stratigraphy and Greenland climate events based on the GICCO5 (after converting b2k age to BP) are indicated at the top and in the bottom, respectively. The timing of the major excursion in $\delta D_{\text {aq }}$ values at $13090 \pm 37$ year BP was estimated using a Bayesian change point procedure 45 . 


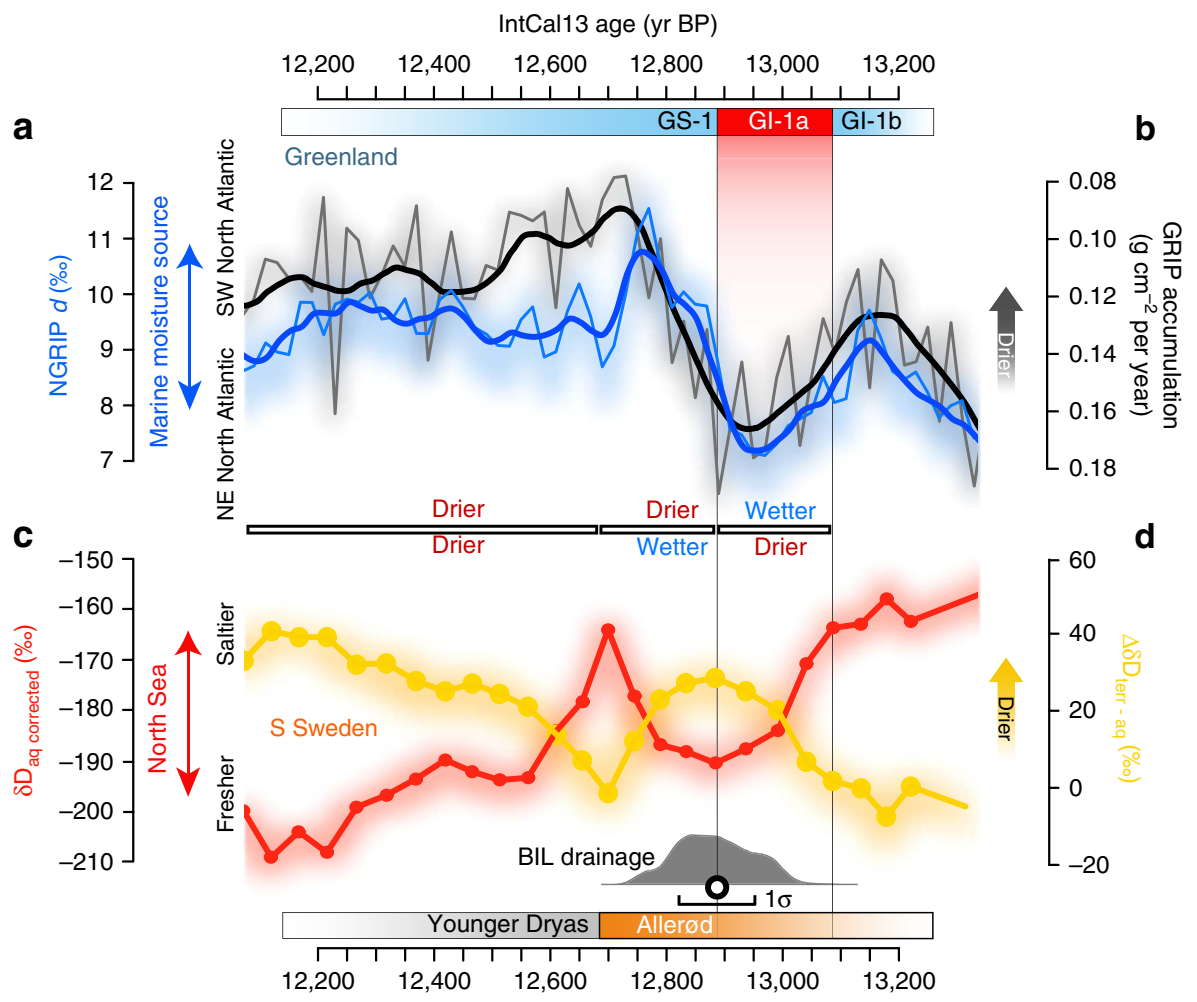

Figure 3 | Comparison between Greenland and Hässeldala hydrological proxies at the onset of the YD pollen zone. Synchronized (a) NGRIP $d$-excess ${ }^{22}$ and (b) GRIP snow accumulation ${ }^{23}$ records compared to Hässeldala (c) $\delta D_{\text {aq }}$ corrected for ice volume, temperature and post-glacial isostatic uplift changes ( $\delta D_{\text {corri }}$ Supplementary Methods), and (d) terrestrial evapotranspiration. The $\delta D_{\text {corr }}$ is a proxy for $\delta D$ of precipitation reflecting anomalies in distillation of the water vapour at the marine moisture source ${ }^{25}$, primarily driven by input of isotopically depleted freshwater. Note that the $\sim 19 \%$ o decrease in $\delta D_{\text {corr }}$ ( $\sim 2.4 \%$ decrease in $\delta^{18} \mathrm{O}$ ) during the late Allerød pollen zone is in agreement with a $-2.5 \%$ shift in $\delta^{18} \mathrm{O}$ recorded in benthic foraminifera off the west coast of Southern Sweden ${ }^{46}$. The temporal evolution of the regional hydrological conditions is also displayed. Greenland records are presented at 20 -year resolution with bold lines indicating the 60 - year moving average. All records are presented with shadings indicating empirical $68 \%$ uncertainty bounds based on analytical and age-model errors. Vertical axes are oriented such that dry conditions plot upwards (note reverse axis for GRIP accumulation). Shown is also the combined probability of a number of calibrated radiocarbon dates constraining the age of the first drainage of the Baltic Ice Lake, inferred from deglaciation of the outlet in south-central Sweden and rapid isolation of lakes in the outlet area at Mt. Billingen (Supplementary Methods). 68\% uncertainty (bar) and median age (circle) are also presented. Records are consistently displayed on the same IntCal13 time scale.

sea-level pressure (SLP) dipole across the North Atlantic with deeper Icelandic low pressure and higher SLP over Northern Europe relative to the preceding phase (Fig. 4). The SLP dipole is a distinct feature in the model and is associated with FIS meltwater forcing only as it is absent when freshwater is discharged from North American sources (Fig. 5). The increased SLP, the surface cooling and the increased sea-ice cover simulated in the Norwegian and Barents Seas (Fig. 4) support the $\sim 2{ }^{\circ} \mathrm{C}$ decline in summer temperatures and progressively drier conditions recorded at $\mathrm{HÄ}$ during GI-1a (Fig. 2). These results are consistent with evidence of cooling recorded in other North European records during the same period $^{27}$. Furthermore, a deeper Icelandic low pressure suggests a closer moisture source for Greenland precipitation, which is consistent with the $\delta^{18} \mathrm{O}$ enrichment in Greenland ice cores during GI-1a. The model output are further supported by highresolution $\delta D$ records from Meerfelder Maar (MFM) in Western Europe $^{17}$, where relatively wetter conditions are inferred during GI-1a, in contrast to drier conditions in Northern Europe (Supplementary Discussion; Supplementary Fig. 4).

\section{Discussion}

In light of our results we argue that persistent FIS ice-mass loss at the end of the AL interstadial and the resulting freshening along the continental shelf of the Nordic Seas, which resulted in an early stage of cooling in Northern Europe, have likely determined the timing of hydrological shifts in Greenland at the GI-1a/GS-1 transition. Analogously to mechanisms invoked for the onset of cold climatic phases during the last glacial cycle ${ }^{9,10}$ and the present interglacial ${ }^{34}$, we posit that when sea ice reached a critical extent in the North Sea, Norwegian and Barents Seas, the excess of sea ice was transported to the subpolar North Atlantic via oceanic recirculation in the Nordic Seas. Potentially a sudden westward drainage of the Baltic Ice Lake through the southcentral Swedish lowlands, as suggested by the available chronological evidence relating to deglaciation of the spillway (Figs 1 and 3; Supplementary Discussion; Supplementary Methods; Supplementary Fig. 9; Supplementary Table 2), may have contributed to drive sea ice and freshwater to the western sector of the Nordic Seas. Recirculation of sea ice in the Nordic Seas could have delivered ice to the subpolar North Atlantic to locations beyond the limits expected from local climatological conditions. The displacement of sea ice would have then caused the aforementioned southward shift of North Atlantic storm tracks at the onset of GS-1 and large-scale colder conditions. The model simulations support this interpretation. High-pressure anomalies over mid-to-high latitudes take place together with a westward and southward migration of sea ice in the North Atlantic (Fig. 5). In contrast, the SLP dipole pattern occurs only 
a

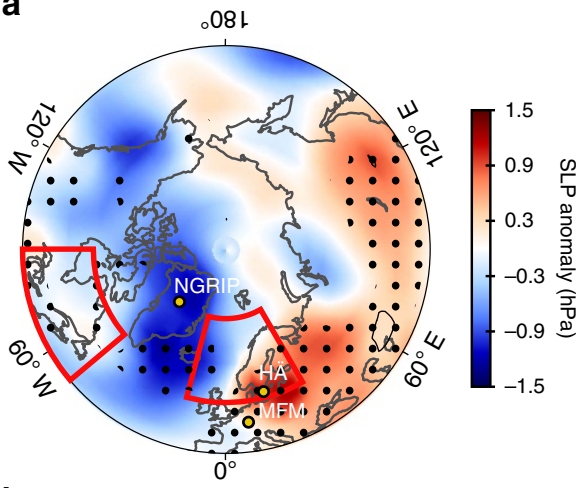

b

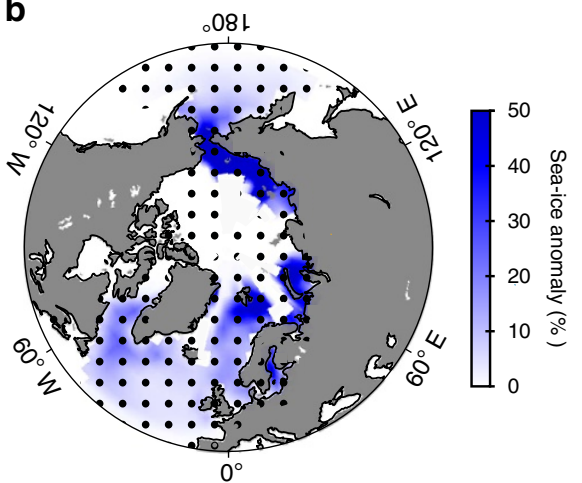

C

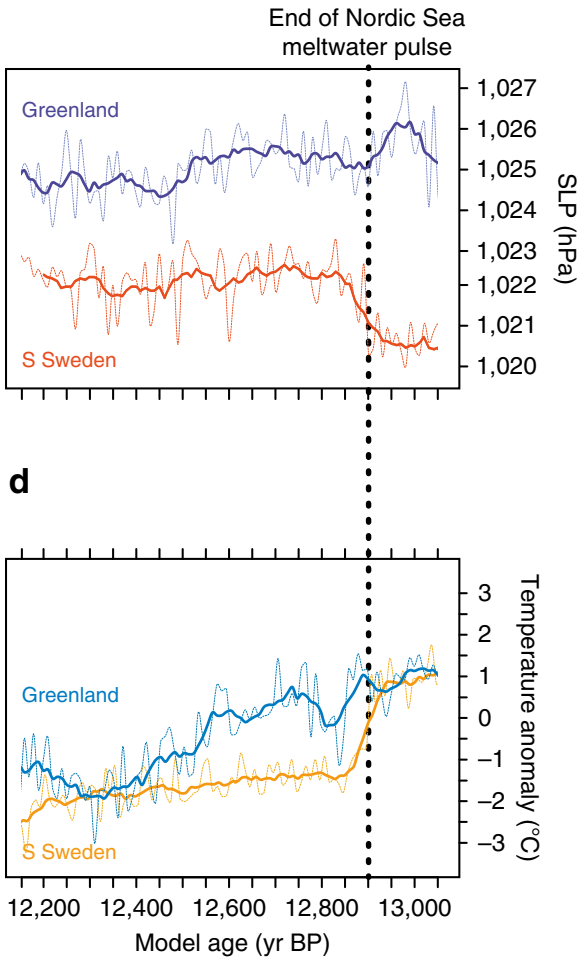

Figure 4 | Modelled climate changes under Fennoscandian Ice Sheet freshwater forcing conditions. Summer changes (JJA) in (a) sea-level pressure and (b) sea-ice cover between the 50 years preceding the abrupt cooling (13,000-12,951 model year BP) and the abrupt transition period (12,940-12,891 model year BP). Significance levels are indicated by black stippling (95\%). Sites referred to in the text are shown. The areas delimited in red show the location where freshwater forcing was prescribed. Time series of summer (c) sea-level pressure and (d) surface temperature decadal mean (light solid line) anomalies averaged over $57.5^{\circ}-76.0^{\circ} \mathrm{N}$ and $20.0^{\circ}-40.0^{\circ} \mathrm{W}$ domain for Greenland and $50.0^{\circ}-65.0^{\circ} \mathrm{N} 5.0^{\circ}-35.0^{\circ} \mathrm{E}$ domain for Sweden, respectively. The bold lines show a 50-year running mean. The dotted line represents the end of the modelled Nordic Sea meltwater pulse. Sea-level pressure anomaly changes were estimated after removing the related global mean.

when sea-ice growth is confined to the eastern sector of the Nordic Seas (Fig. 4; Supplementary Figs 10 and 11). However, further studies are required to conclusively attribute a rapid export of sea-ice excess into the subpolar North Atlantic to a nonlinear behaviour of sea-ice growth in the eastern Nordic Seas or to a catastrophic meltwater discharge.

In conclusion, we provide a plausible mechanism for the linkages between FIS freshwater inputs to the Nordic Seas and North Atlantic hydroclimate patterns, reconciling the timing of freshwater forcing with the major isotopic excursions recorded in Greenland ice cores at the end of the Last Termination. Altogether, we suggest a new coherent concept for the inception of GS-1 and ultimately the YD, which may be critical to gauge future climate simulations.

\section{Methods}

Chronology. The chronology was established using a composite Bayesian age model based on 49 AMS ${ }^{14} \mathrm{C}$ dates from terrestrial plant macrofossils. $21{ }^{14} \mathrm{C}$ dates were transferred from a previously studied core ${ }^{35}$ by correlating total organic content records via a Monte Carlo alignment method ${ }^{12}$. At $\mathrm{HÄ}$, core correlation is facilitated by the small size of the basin, which extends over an area of approximately $20 \mathrm{~m}^{2}$, resulting in total organic content records from adjacent cores to exhibit the same high resolution and identifiable lithostratigraphic patterns (for example, ref. 12).

Lipid biomarker analysis. Fifty-four freeze-dried samples $\left(\sim 8 \mathrm{~cm}^{3}\right)$ were extracted from the sediments via sonication with dichloromethane: methanol (9:1) for $20 \mathrm{~min}$; and subsequent centrifugation. This was repeated three times and supernatants were combined. Aliphatic hydrocarbon fractions were isolated from the total lipid extract using silica gel columns (5\% deactivated) that were eluted with pure hexane. The saturated hydrocarbon fraction was separated by desulphurization over $10 \% \mathrm{AgNO}_{3}-\mathrm{SiO}_{2}$ silica gel using pure hexane as eluent. Saturated hydrocarbon fractions were analysed by gas chromatography-mass spectrometry for identification and quantification, using a Shimadzu GCMSQP2010 Ultra. Isotope ratios were determined using a Thermo Finnigan Delta XL mass

spectrometer and all analyses were performed in triplicate. A standard mixture of $n$-alkanes with known $\delta D$ composition (mix A4, provided by A. Schimmelmann, Indiana University, USA) was run several times daily to calibrate the $\mathrm{CO}_{2}$ reference gas used for conversion of $\delta D$ values to VSMOW scale.

Chironomid analysis. Samples for chironomid analysis of the HÄ sequence were taken every $2 \mathrm{~cm}$. The aim was to obtain over 100 head capsules for each sample. Studies have demonstrated that 50 head capsules are an adequate minimum to establish species diversity in a sample and to provide reliable temperature estimates $^{36,37}$. In most samples, $1-2 \mathrm{~g}$ of sediment was sufficient to obtain over 100 head capsules. The chironomid larval head capsules were prepared for identification following the procedure in Brooks et al..$^{38}$ The head capsules were identified using a compound microscope at $\times 100$ to $\times 400$ magnification, with reference to Cranston ${ }^{39}$, Wiederholm ${ }^{40}$, Rieradevall and Brooks ${ }^{41}$ and Brooks et $a l .{ }^{42} \mathrm{~A}$ modern Norwegian temperature calibration data set was used to derive the chironomid-inferred temperatures (ref. 43, and unpublished). Root-meansquared-error of prediction (RMSEP) of the 2-component WA-PLS inference model was $1.12^{\circ} \mathrm{C}$, the coefficient of determination $\left(\mathrm{r}^{2}\right)$ was 0.92 and the maximum bias was $0.77^{\circ} \mathrm{C}$

Model description. We analysed the simulation of the Transient Climate of the last $21 \mathrm{kyr}$ (refs 33,44) (TraCE-21ka). To perform this experiment the National Center for Atmospheric Research (NCAR) Community Climate System Model 3 (CCSM3) has been used. The atmospheric model is the Community Atmospheric Model 3 with $3.75^{\circ} \times 3.75^{\circ}$ horizontal resolution and 26 hybrid vertical levels. The ocean model is the NCAR implementation of the Parallel Ocean Program with 25 vertical levels. The longitudinal resolution of the ocean model is $3.6^{\circ}$ and the latitudinal resolution is variable, with finer resolution near the equator $\left(\sim 0.9^{\circ}\right)$. The model is coupled to a dynamic global vegetation module. The model is forced 

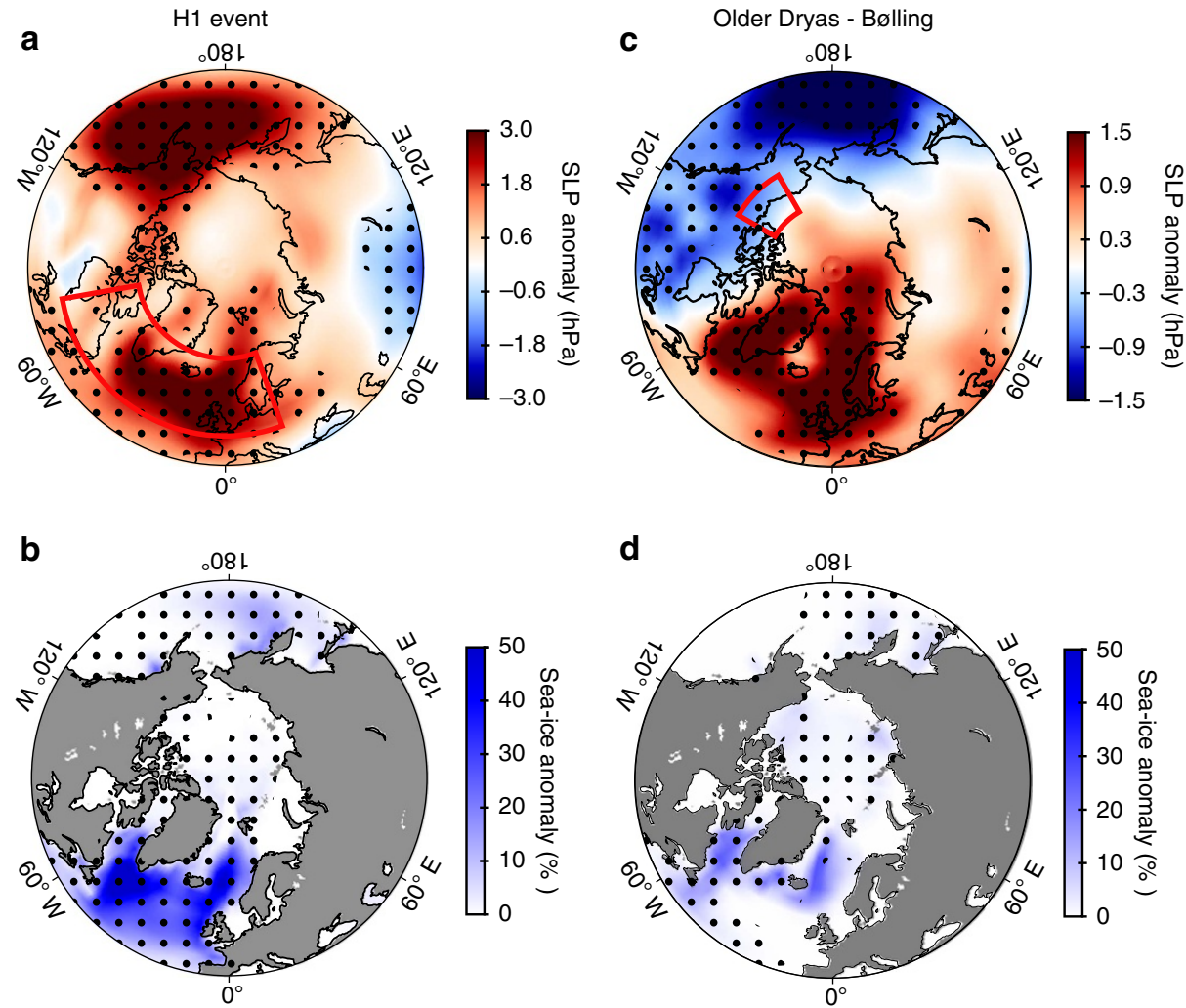

Figure 5 | Modelled change in SLP and Sea Ice under Laurentide Ice Sheet freshwater forcing conditions. Summer changes (JJA) in (a) sea-level pressure and (b) sea-ice cover during Henrich Event 1 (H1), calculated comparing the Last Glacial Maximum mean state (19,050-19,000 model year BP) and the $\mathrm{H} 1$ climatology $(17,050-17,000$ model year BP). (c,d) Same as in $\mathbf{a}$ and $\mathbf{b}$ for the model counterpart of the Bølling-Older Dryas pollen-stratigraphic transition (14,250-14,200 minus 14,350-14,300 model year BP). Significance levels are indicated by black stippling (95\%). The area delimited in red shows the region where meltwater forcing was prescribed in the model. Sea-level pressure anomaly changes were estimated after removing the related global mean.

by realistic insolation, atmospheric $\mathrm{CO}_{2}$, continental ice sheets and meltwater discharge as described in details in Liu et al..$^{33}$ (Supplementary Table 3). The model is able to consistently replicate many major features of the deglacial surface temperature evolution in agreement with reconstructions from various proxy records over the globe. The model reproduces the Northern Hemisphere cooling from the LGM into Heinrich 1 event, the abrupt warming into the Bølling-Allerød warm periods, the cooling into the Younger Dryas, and hence the following recovery to the warm climate into the Holocene ${ }^{33}$.

\section{References}

1. Broecker, W. S. et al. The routing of Laurentide ice-sheet meltwater during the Younger Dryas cold event. Nature 341, 318-321 (1989).

2. Alley, R. B. et al. Abrupt increase in Greenland snow accumulation at the end of the Younger Dryas event. Nature 362, 527-529 (1993).

3. Murton, J. B., Bateman, M. D., Dallimore, S. R., Teller, J. T. \& Yang, Z. Identification of Younger Dryas outburst flood path from Lake Agassiz to the Arctic Ocean. Nature 464, 740-743 (2010).

4. Lowell, T. et al. Testing the Lake Agassiz meltwater trigger for the Younger Dryas. EOS Trans. Am. Geophys. Union 86, 365-372 (2005).

5. Fisher, T. G., Waterson, N., Lowell, T. V. \& Hajdas, I. Deglaciation ages and meltwater routing in the Fort McMurray region, northeastern Alberta and northwestern Saskatchewan, Canada. Quat. Sci. Rev. 28, 1608-1624 (2009).

6. Not, C. \& Hillaire-Marcel, C. Enhanced sea-ice export from the Arctic during the Younger Dryas. Nat. Commun. 3, 647 (2012).

7. Breckenridge, A. The Tintah-Campbell gap and implications for glacial Lake Agassiz drainage during the Younger Dryas cold interval. Quat. Sci. Rev. 117, 124-134 (2015).

8. Li, C., Battisti, D. S. \& Bitz, C. M. Can North Atlantic sea ice anomalies account for Dansgaard-Oeschger climate signals? J. Clim. 23, 5457-5475 (2010).

9. Dokken, T. M., Nisancioglu, K. H., Li, C., Battisti, D. S. \& Kissel, C. DansgaardOeschger cycles: interactions between ocean and sea ice intrinsic to the Nordic seas. Paleoceanography 28, 491-502 (2013).
10. Singh, H. A., Battisti, D. S. \& Bitz, C. M. A heuristic model of dansgaardoeschger cycles. part i: Description, results, and sensitivity studies. J. Clim. 27, 4337-4358 (2014).

11. Wohlfarth, B. et al. Constraining the age of Lateglacial and early Holocene pollen zones and tephra horizons in southern Sweden with Bayesian probability methods. J. Quat. Sci. 21, 321-334 (2006).

12. Muschitiello, F., Andersson, A., Wohlfarth, B. \& Smittenberg, R. H. The C20 highly branched isoprenoid biomarker-A new diatom-sourced proxy for summer trophic conditions? Org. Geochem. 81, 27-33 (2015).

13. Gustafsson, M., Rayner, D. \& Chen, D. Extreme rainfall events in southern Sweden: Where does the moisture come from? Tellus A 62, 605-616 (2010).

14. Björck, S. et al. Synchronized TerrestrialAtmospheric Deglacial Records Around the North Atlantic. Science 274, 1155-1160 (1996).

15. Drenova, A. N., Timireva, S. N. \& Chikolini, N. I. Late glacial dune-building in the Russian plain. Quat. Int. 41-42, 59-66 (1997).

16. Sachse, D., Radke, J. \& Gleixner, G. Hydrogen isotope ratios of recent lacustrine sedimentary n-alkanes record modern climate variability. Geochim. Cosmochim. Acta 68, 4877-4889 (2004).

17. Rach, O., Brauer, A., Wilkes, H. \& Sachse, D. Delayed hydrological response to Greenland cooling at the onset of the Younger Dryas in western Europe. Nat. Geosci. 7, 109-112 (2014).

18. Gat, J. R. Oxygen and hydrogen isotopes in the hydrologic cycle. Annu. Rev. Earth Planet. Sci. 24, 225-262 (1996).

19. Sachse, D. et al. Molecular Paleohydrology: interpreting the hydrogen-isotopic composition of lipid biomarkers from photosynthesizing organisms. Annu. Rev. Earth Planet. Sci. 40, 221-249 (2012).

20. Muscheler, R., Adolphi, F. \& Knudsen, M. F. Assessing the differences between the IntCal and Greenland ice-core time scales for the last 14,000 years via the common cosmogenic radionuclide variations. Quat. Sci. Rev. 40, 1-7 (2014).

21. Rasmussen, S. O. et al. A new Greenland ice core chronology for the last glacial termination. J. Geophys. Res. Atmos 111, D06102 (2006).

22. Steffensen, J. P. et al. High-resolution greenland ice core data show abrupt climate change happens in few years. Science 321, 680-684 (2008). 
23. Johnsen, S. J., Dahl-Jensen, D., Dansgaard, W. \& Gundestrup, N. Greenland palaeotemperatures derived from GRIP bore hole temperature and ice core isotope profiles. Tellus B 47, 624-629 (1995).

24. Pfahl, S. \& Sodemann, H. What controls deuterium excess in global precipitation? Clim. Past 10, 771-781 (2014).

25. Hammarlund, D., Barnekow, L., Birks, H., Buchardt, B. \& Edwards, T. Holocene changes in atmospheric circulation recorded in the oxygen-isotope stratigraphy of lacustrine carbonates from northern Sweden. Holocene 12, 339-351 (2002).

26. Dirmeyer, P. A. \& Brubaker, K. L. Evidence for trends in the Northern Hemisphere water cycle. Geophys. Res. Lett. 33, L14712 (2006).

27. Muschitiello, F. \& Wohlfarth, B. Time-transgressive environmental shifts across Northern Europe at the onset of the Younger Dryas. Quat. Sci. Rev. 109, 49-56 (2015).

28. Schrum, C. Regionalization of climate change for the North Sea and Baltic Sea. Clim. Res. 18, 31-37 (2001).

29. Karpuz, N. K. \& Jansen, E. A high-resolution diatom record of the last deglaciation from the SE Norwegian Sea: Documentation of rapid climatic changes. Paleoceanography 7, 499-520 (1992).

30. Jiang, H. \& Nordberg, K. Late Weichselian environmental changes of the southern Kattegat, Scandinavia, inferred from diatom records. Geol. Soc. Spec. Publ. 111, 245-260 (1996).

31. Klitgaard-Kristensen, D., Sejrup, H. P. \& Hafiidason, H. The last $18 \mathrm{kyr}$ fluctuations in Norwegian Sea surface conditions and implications for the magnitude of climatic change: evidence from the North Sea. Paleoceanography 16, 455-467 (2001).

32. Ebbesen, H. \& Hald, M. Unstable Younger Dryas climate in the northeast North Atlantic. Geology 32, 673-676 (2004).

33. Liu, Z. et al. Transient simulation of last deglaciation with a new mechanism for Bølling-Allerød warming. Science 325, 310-314 (2009).

34. Lehner, F., Born, A., Raible, C. C. \& Stocker, T. F. Amplified inception of European Little Ice Age by sea ice-ocean-atmosphere feedbacks. J. Clim. 26, 7586-7602 (2013).

35. Davies, S. M. et al. Were there two Borrobol Tephras during the early Lateglacial period: Implications for tephrochronology? Quat. Sci. Rev. 23, 581-589 (2004).

36. Heiri, O. \& Lotter, A. F. Effect of low count sums on quantitative environmental reconstructions: an example using subfossil chironomids. J. Paleolimnol. 26, 343-350 (2001).

37. Quinlan, R. \& Smol, J. P. Setting minimum head capsule abundance and taxa deletion criteria in chironomid-based inference models. J. Paleolimnol. 26, 327-342 (2001).

38. Brooks, S. J., Mayle, F. E. \& Lowe, J. J. Chironomid-based Lateglacial climatic reconstruction for southeast Scotland. J. Quat. Sci. 12, 161-167 (1997).

39. Cranston, P. S. A key to the larvae of the British Orthocladiinae (Chironomidae) (Freshwater Biological Association Ambleside, 1982).

40. Wiederholm, T. Chironomidae of the Holarctic region. Keys and diagnoses. Part 1. Larvae. Entomol. Scand. Suppl. 1-457 (1983).

41. Rieradevall, M. \& Brooks, S. J. An identification guide to subfossil Tanypodinae larvae (Insecta: Diptera: Chrironomidae) based on cephalic setation. J. Paleolimnol. 25, 81-99 (2001).

42. Brooks, S. J., Langdon, P. G., Heiri, O. \& Association, Q. R. The identification and use of Palaearctic Chironomidae larvae in palaeoecology (Quaternary Research Association, 2007).
43. Brooks, S. J. \& Birks, H. J. B. Chironomid-inferred air temperatures from Lateglacial and Holocene sites in north-west Europe: progress and problems. Quat. Sci. Rev. 20, 1723-1741 (2001).

44. He, F. et al. Northern Hemisphere forcing of Southern Hemisphere climate during the last deglaciation. Nature 494, 81-85 (2013).

45. Erdman, C. \& Emerson, J. W. bcp: an R package for performing a Bayesian analysis of change point problems. J. Stat. Softw. 23, 1-13 (2007).

46. Bodén, P., Fairbanks, R. G., Wright, J. D. \& Burckle, L. H. High-resolution stable isotope records from southwest Sweden: The drainage of the Baltic Ice Lake and Younger Dryas Ice Margin Oscillations. Paleoceanography 12, 39-49 (1997).

\section{Acknowledgements}

We thank M. Kylander, M. Steinthorsdottir and N. van der Putten for coring, J. Rattray for assistance with organic geochemical analysis and A. Hägglund for assistance with GC-IRMS analysis. We are also grateful to four anonymous reviewers for helpful comments on an earlier version of the manuscript. Chironomid-inferred temperature reconstructions were undertaken as part of a $\mathrm{PhD}$ project by J.E. Watson (Queen's University Belfast) and funded by DEL (Department for Employment and Learning, Northern Ireland). This work forms part of the Climate Transition Project financed by the Swedish Nuclear Fuel and Waste Management Company. It is a contribution to the INTIMATE project. Thumbnail image by B. Eriksson.

\section{Author contributions}

F.M. conceived the study, performed the isotope analysis, led the writing and produced the figures. F.S.R.P. designed and performed the model analysis and contributed to the interpretation of the proxy data. J.E.W. performed the chironomid analysis. R.H.S. contributed to biomarker data evaluation. A.A.M.S. analysed the air back trajectory data. S.J.B. and N.J.W. contributed to the temperature data evaluation. A. K. performed pollen counting. B.W. provided the background data for HÄ, the necessary financial support and insight into local and regional paleoclimate and paleoenvironment. All authors contributed in editing of the manuscript.

\section{Additional information}

Supplementary Information accompanies this paper at http://www.nature.com/ naturecommunications

Competing financial interests: The authors declare no competing financial interests.

Reprints and permission information is available online at http://npg.nature.com/ reprintsandpermissions/

How to cite this article: Muschitiello, F. et al. Fennoscandian freshwater control on Greenland hydroclimate shifts at the onset of the Younger Dryas. Nat. Commun. 6:8939 doi: 10.1038/ncomms9939 (2015).

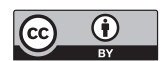

This work is licensed under a Creative Commons Attribution 4.0 International License. The images or other third party material in this article are included in the article's Creative Commons license, unless indicated otherwise in the credit line; if the material is not included under the Creative Commons license, users will need to obtain permission from the license holder to reproduce the material. To view a copy of this license, visit http://creativecommons.org/licenses/by/4.0/ 